\title{
Integrated system approach to improving the efficiency of IT projects management based on evolutionary modeling
}

\author{
A.A.Zakharova ${ }^{1}$, K.V.Zakharchenkov², Yu.V.Vaynilovich ${ }^{2}$ \\ zaa@tu-bryansk.ru, zaharchenkovkv@mail.ru, Ylia.v@tut.by \\ ${ }^{1}$ Bryansk State Technical University, Bryansk, Russia \\ ${ }^{2}$ Inter-State Educational Institution of Higher Education «Belarusian-Russian University», Mogilev, Belarus
}

\begin{abstract}
The concept of improving the efficiency of IT projects management is proposed, based on an integrated system approach to IT projects management and implementing a rational choice of parameters of the IT projects management system. The described approach provides integrated information processing and support for management decision-making at all stages of the IT project implementation. The integrated system approach to improving the efficiency of IT projects management involves the development of new algorithms for forming structure and composition of project teams and distribution of project team participants to project tasks using evolutionary modeling. The advantage of the proposed approach is the ability to quickly respond to changes in the parameters of internal processes of an IT project and an external environment. The proposed approach was tested when creating the corporate information system of "SMIT-Yartsevo" LLC. The application of the proposed approach at "SMIT-Yartsevo" LLC ensured the reduction in the labor intensity and timing of the implementation of the main stages of the project to create the corporate information system by increasing the efficiency of managing the formation of project teams and the distribution of tasks among project team participants.
\end{abstract}

Keywords: IT projects management, evolutionary modeling, project team, project tasks.

\section{Introduction}

The IT projects management system is an active system $[1,2]$, the conceptual model of which can be described by the following parameters: personal qualities, knowledge, skills of project team participants, structure and composition of project teams, structure and composition of project tasks, project management methods and technologies.

Approaches to improving the efficiency of IT projects management can affect any of the listed parameters of the IT project model.

IT project management, in accordance with the Agile methodology [3], has the following specific features:

- significant influence of personal and psychological qualities of project team participants on the effectiveness of project tasks solution;

- the need to constantly change the composition and structure of project tasks depending on changes in customer requirements;

- the constant change in customer requirements necessitates the use of flexible development methodologies that allow dynamic redistribution of tasks between performers in the project implementation process.

Prihozhy A. A., Zhdanouski A. M. proposed to increase the efficiency of IT projects management by optimizing development teams by evaluating their professional competencies taking into account the requirements for a specific project [4].

For optimal distribution of applicant programmers in the team in order to improve the quality of IT projects implementation, Ostroukh E.N. offers an approach based on a combination of the classical model of resource allocation, the Bee Colony algorithm, the Belbin R.M. Team Roles Theory and the accounting of professional qualities [5].

Artemov O. V. approaches the formation of teams from the position of socionics: the presence of leadership relationships, role composition [6]. The professional competencies of project participants are not taken into account.

The above approaches ensure the improvement of project management efficiency by managing the composition of project team participants.

Budyl'skiy A.V. explores the problem of distribution of resources among project tasks and replacing them [7].

Antonova A. S. and Burkova I. V. develop new approaches to planning business processes and project work. Project management efficiency is improved by creating new planning methods $[8,9]$.

An analysis of existing approaches to improving the efficiency of IT projects management showed that efficiency is achieved by optimizing certain aspects of the IT projects management task and there are no integrated system approaches that implement a rational choice of parameters of the IT projects management system, providing integrated information processing and support for management decision-making at all stages of the project implementation.

The developed concept implies a transition from improving the efficiency of IT projects management by improving the efficiency of solving individual tasks to an integrated increase in the efficiency of IT projects management based on a set of interconnected methods.

The main advantage of the proposed concept is its flexibility: the ability to quickly and efficiently respond to both external (changing customer requirements) and internal (project team composition) changes.

The proposed concept provides solving the scientific problem of increasing efficiency of IT projects management using SADT methodology, cluster analysis, COCOMO II method [10] (modified on the basis of T. Saati's paired comparison method), the method of expert estimates [11], evolutionary modeling algorithms $[12,13]$, and multilevel quality control of project tasks solving. 


\section{Theoretical foundations of IT projects management concept based on evolutionary modeling}

The concept of improving the efficiency of IT projects management is based on further development of the Agile software development management methodology [3], further development of methods for building project teams that comprehensively take into account behavioral and professional competencies [14, 15], of methods for allocating resources to project tasks with the purpose to improve the efficiency of IT projects management with the adaptation of evolutionary modeling algorithms to solve these problems, and the methodology of structural analysis, labor cost estimation.

The proposed concept is based on the following principles:

1. an integrated approach to the synthesis of the structure and composition of project teams, combining the accounting of behavioral [14, 15] and professional competencies of candidates for participation in the implementation of the project using evolutionary modeling algorithms in combination with COCOMO II method and T. Saati's paired comparison method with the adjustment of algorithms parameters when changing system and external environment parameters;

2. synthesis of the composition and structure of the project tasks taking into account the integrated processing of information on the distribution of project team participants for tasks by adapting evolutionary modeling algorithms in combination with COCOMO II method and the T. Saati's paired comparison method to solve this task;

3. an integrated support for decision-making at each step of the IT project implementation when changing system (composition and structure of participants) and external (composition and structure of tasks) factors by dynamically configuring the parameters of evolutionary modeling algorithms.

Improvement of IT projects management efficiency, in accordance with the proposed concept, is carried out by means of an integrated system approach to IT projects management that includes the formation of project teams and the distribution of IT project participants for tasks using evolutionary modeling algorithms and multilevel quality control of solving project tasks.

The distinctive features of the presented concept of improving the efficiency of IT projects management are:

1. an integrated system approach to improving the efficiency of IT projects management using modified evolutionary modeling algorithms to support decisionmaking in the process of:

- synthesizing the composition and structure of project teams, taking into account the behavioral and professional competencies of candidates for participation in projects;

- synthesizing the structure and composition of project tasks and allocating project team participants to tasks taking into account professional competencies. The degree of competencies ownership is determined based on the results of a multilevel assessment of the quality of solving project tasks;

2. integrated processing of information on the personal and psychological qualities of project participants, labor intensity and complexity of solving project tasks to reduce the number of iterations using adaptive evolutionary modeling algorithms that allows ensuring the fastest and most efficient formation of project teams and the distribution of participants in IT project teams to tasks.

A structural diagram of the concept of improving the efficiency of IT projects management based on adaptive evolutionary modeling algorithms is presented in Fig. 1.

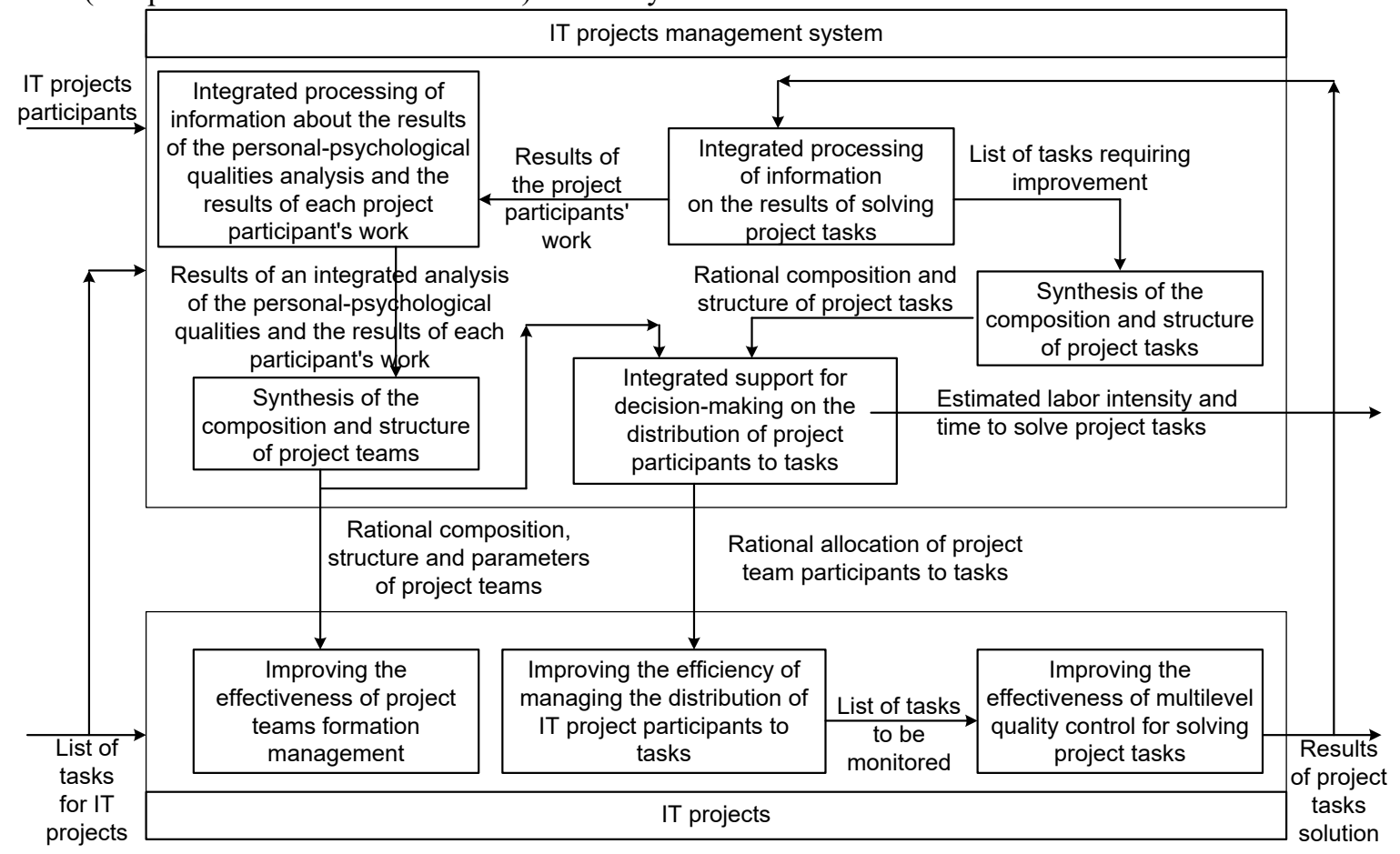

Fig. 1. A structural diagram of the concept of improving the efficiency of IT projects management based on adaptive evolutionary modeling algorithms 
Management of IT-project as socio-economic system involves dynamic change of parameters of control processes when parameters of internal processes of ITproject and parameters of external environment change. In accordance with the proposed concept, improving the efficiency of IT projects management is provided by configuring the parameters of evolutionary modeling algorithms in the process of implementing IT projects, depending on changes in the internal parameters of the IT project processes and external environment parameters.

Improving efficiency by applying new approaches to solving IT projects management tasks is carried out at the following stages of project implementation: the formation of project teams, the distribution of project team participants to tasks, multilevel quality control of tasks solving.

To solve the problems of forming project teams and distributing project team participants to tasks in the management of IT projects, algorithms have been developed to improve the efficiency of management based on evolutionary modeling, providing the possibility of implementing the main principles and features of the proposed concept. The developed algorithms are implemented in a software complex for multilevel IT projects management [16].

\section{Formalization of the posing of the task of improving the IT projects management efficiency}

In accordance with the proposed concept, the IT project is characterized by the following set: ITproject $=\langle$ Tasks, Participants $\rangle$,

where Tasks - the set of project tasks, Participants - the set of project teams participants.

Each project task is characterized by the following set: Task $=\left\langle\right.$ Priority, Tech $_{\text {Task }}$, Complexity $\left.{ }_{\text {Task }}, \mathrm{P}_{\mathrm{UFD}}\right\rangle$, (2) where Priority is the priority of the task, Tech Task $_{\text {is }}$ technologies and tools used, Complexity Task $_{\text {is }}$ ise complexity of the task, $P_{U F D}$ is the probability of detecting errors by the user.

The participants of project teams are characterized by the following set:

Participant $=\left\langle\right.$ Level $_{\text {Tech }}$, Experience $\rangle$,

where Level $_{\text {Tech }}$ is the level of knowledge of technologies and tools, Experience is experience with technologies and tools.

Quality function for solving project tasks:

$$
\mathrm{P}_{\text {UserDefect }}=\frac{\text { UserFindDefect }}{\text { AllFindDefects }} \rightarrow \mathrm{min} \text {, }
$$

where UserFindDefects is the number of errors in the program detected by users; AllFindDefects is the total number of errors in the program detected during the program operation.
The objective function of the task of improving the IT projects management efficiency

Pmitpr $=$ EvMod (Task, Participants $) \rightarrow$ min,

where PMitpr is the IT project labor intensity.

The use of evolutionary modeling makes it possible to select the values of IT projects parameters that reduce labor intensity.

\section{Improving the efficiency of managing the formation of the structure and composition of IT projects teams}

The process of forming a project team is the task of selecting project team participants taking into account their personal and psychological qualities, qualifications and specialization.

The scheme of the project team formation management process is shown in fig. 2 .

The team composition is considered rational if it provides the greatest efficiency in terms of project implementation in the opinion of the project manager, as a decision-maker. In the process of evolutionary modeling, several variants of the composition of project teams are formed. When deciding on the composition of the project team, the project manager can take into account a number of factors that cannot be taken into account in the process of evolutionary modeling.

The features of the proposed scheme of the process of controlling the formation of the structure and composition of project teams are listed below.

1. Integrated processing of information about project teams participants based on the analysis of personal and psychological qualities using methods of cluster analysis, of knowledge, skills and abilities of project teams participants by applying methods of processing the results of solving project tasks. Pre-processing of information accelerates the work of evolutionary modeling algorithms.

2. Synthesis of the rational composition and structure of project teams based on evolutionary modeling with the formation of a system of restrictions due to the specifics of IT projects, in the process of configuring the parameters of evolutionary modeling algorithms in combination with the use of COCOMO II method and T. Saati's paired comparison method by for estimation of project labor intensity.

The proposed scheme of the process of controlling the formation of the structure and composition of IT project teams provides integrated processing of information about candidates for participation in projects and increases the effectiveness of management decisions when forming project teams by the decision-maker. 


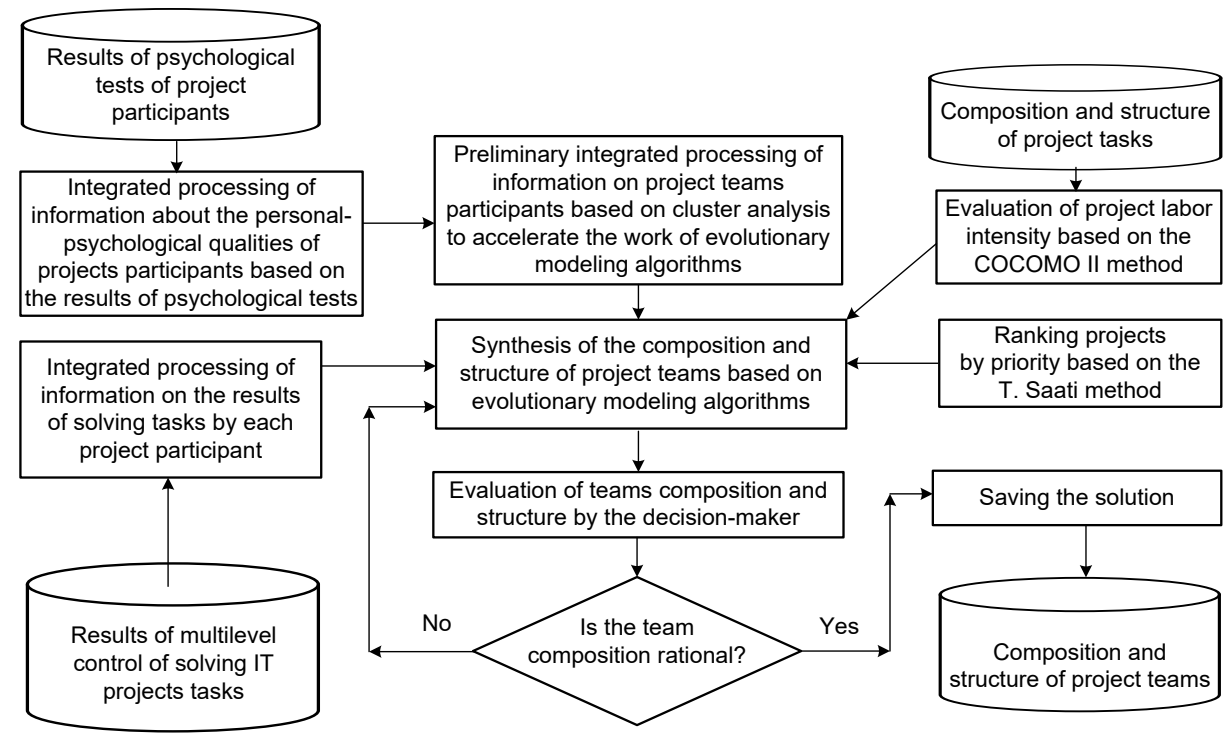

Fig. 2. Scheme of the process of managing the formation of the structure and composition of IT projects teams

\section{Improving the efficiency of managing the distribution of IT projects teams participants to tasks}

The process of managing the distribution of IT projects teams participants to tasks involves determining the composition and structure of project tasks, taking into account the rational distribution of project team participants to tasks.

The scheme for solving the problem is shown in Fig. 3.

The features of the proposed scheme of the process of managing the distribution of projects teams participants to tasks are listed below.

1. Integrated information processing in the synthesis process the composition and structure of project tasks using SADT methodology for decomposing the task into subtasks, COCOMO II method for estimation of the project labor intensity in combination with $\mathrm{T}$.
Saati's paired comparison method to evaluate the complexity of tasks. The proposed information processing procedure provides a comprehensive assessment of the feasibility of decomposing project tasks into subtasks in terms of the labor intensity of IT projects as a whole. The results obtained are the initial data for evolutionary modeling algorithms used in the distribution of participants in IT projects teams to tasks.

2. Distribution of projects teams participants to tasks using evolutionary modeling algorithms with the formation of a system of restrictions due to the specifics of IT projects, in the process of configuring the parameters of evolutionary modeling algorithms. The proposed scheme of the process for managing the allocating of IT projects teams participants to tasks provides integrated information processing and improves the efficiency of management decisions when forming the composition and structure of project tasks, assigning of IT projects teams participants to tasks. 


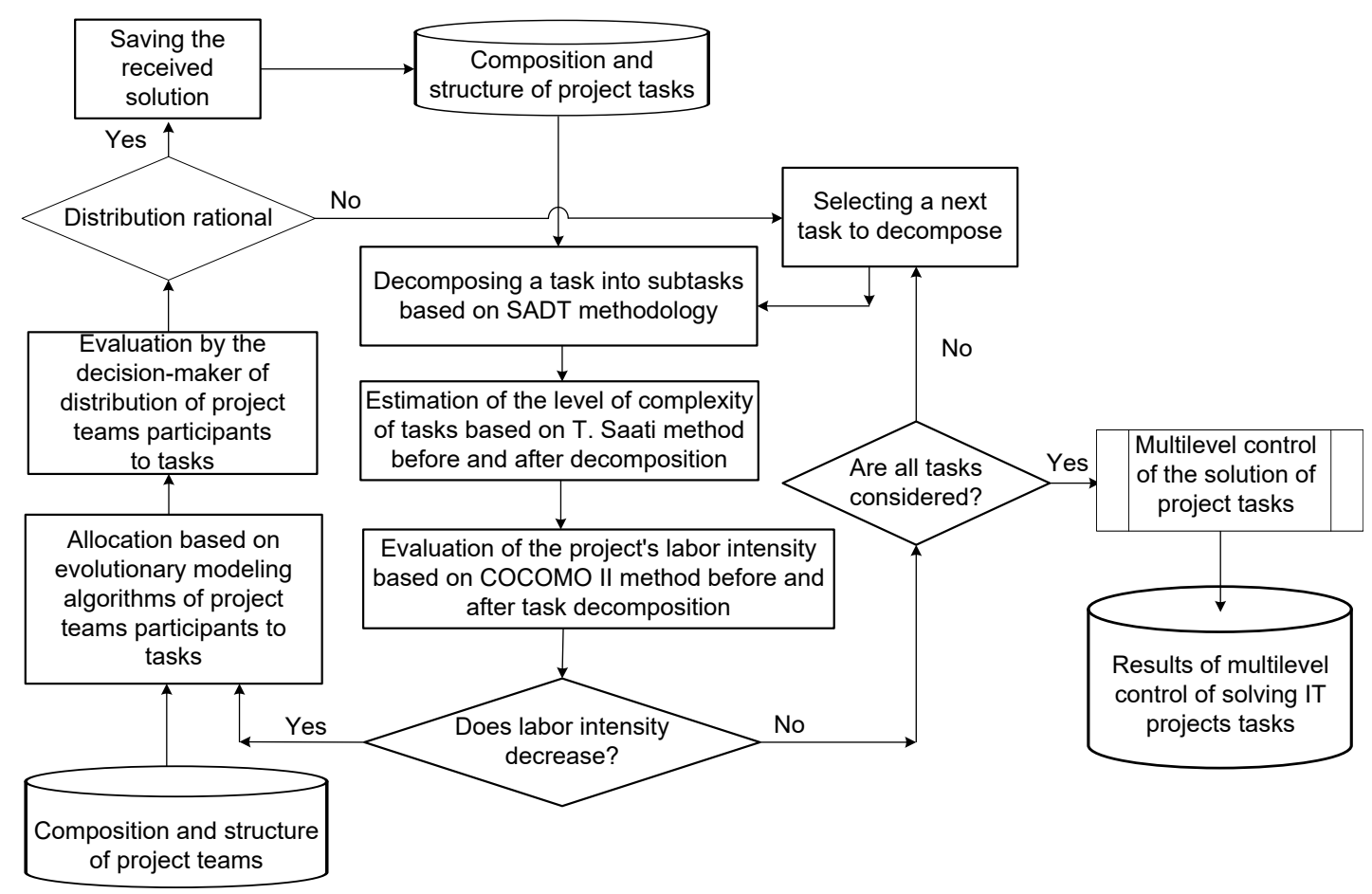

Fig. 3. Scheme of the process for managing the allocating of IT projects teams participants to tasks

\section{Approbation of the proposed approach while improving the efficiency of projects management for the creation of corporate information systems}

The proposed approach to improving the efficiency of IT projects management was implemented when creating the corporate information system (CIS) of "SMITYartsevo" LLC. The purpose of the IT project was to improve the efficiency of management processes through automation. In the process of automation, a preliminary assessment of the effectiveness of algorithms for planning processes in the CIS and a rational choice of algorithms' parameters were carried out [17].

To implement the project to create the CIS in accordance with the proposed integrated system approach, the project manager formed a team of developers. When forming the team, in addition to professional competencies, the personal and psychological qualities of the developers were taken into account.

The composition and structure of the project tasks corresponded to the classic functionality of the ERP system. In the CIS of "SMIT-Yartsevo" LLC were implemented product specification processes in a specialized pricing module, sales and production planning, demand management, material requirements planning, material supply planning. Each task of the development of CIS has been decomposed into subtasks. The composition and structure of the tasks was optimized in terms of minimizing the labor intensity and time of the project implementation. COCOMO II method was used to assess the labor intensity of tasks solving.

Traditional approaches to the implementation of CIS are aimed at changing the business processes of the enterprise to adapt to one of the standard CIS configurations. A distinctive feature of the IT project for the creation of the CIS of "SMIT-Yartsevo" LLC was the automation of management processes adapted to the business processes of the enterprise. During the development of the system, the algorithms of management processes implemented in the CIS were optimized from the point of view of production and economic indicators of the enterprise.

Multilevel testing of CIS modules was performed by employees and heads of structural divisions of "SMITYartsevo" LLC. Based on the results of the assessment of the quality of work, the project manager was made decisions to change the composition of the project team participants.

The development of the CIS of "SMIT-Yartsevo" LLC made it possible to ensure an annual increase in sales of products by $20 \%$, reduce the number of products not completed by the time they were launched into production by $50 \%$, and reduce the number of orders that were not completed on time by $80 \%$.

The estimated economic effect obtained by applying the proposed integrated system approach to improving the efficiency of IT project management in combination with integrated production automation amounted to about 4 million Russian rubles (the estimated economic effect confirmed by the act of implementation).

\section{Conclusion}

The new concept of improving the efficiency of IT project management is proposed, based on the integrated system approach to IT project management, including the formation of the structure and composition of project teams and the distribution of project team participants to project tasks using evolutionary modeling algorithms.

As a result of applying the proposed concept of improving management efficiency in the implementation of educational IT projects [19], in addition to reducing the 
labor intensity of project implementation, significant improvement of quality indicators of training of ITspecialists was noted [19].

The use of the proposed integrated system approach in the creation of the CIS of "SMIT-Yartsevo" LLC made it possible to ensure an increase in the efficiency of managing the formation of project teams and the distribution of tasks among the participants in the project teams. The implementation of the project on the creation of the CIS of "SMIT-Yartsevo" LLC ensured the increase in sales volumes, the reduction in the number of products not completed by the time of launch into production and the reduction in the number of orders not completed on time [17]. The annual economic effect of the introduction of the CIS of "SMIT-Yartsevo" LLC using the proposed approach amounted to about 4 million Russian rubles.

\section{Acknowledgments}

The reported study was funded by RFBR, project number 19-07-00844.

\section{References}

[1] Novikov, D. A., Petrachkov, S.N. Active Systems Theory Course. SINTEG, Moscow (1999). (In Russ.)

[2] Novikov, D. A. Project management: organizational mechanisms. PMSOFT, Moscow (2007). (In Russ.)

[3] Kon, M. Agile: project evaluation and planning. OOO “Al'pina Didzhital”, Moscow (2018). (In Russ.)

[4] Prihozhy, A. A., Zhdanouski, A. M. Method of qualification estimation and optimization of professional teams of programmers. System analysis and applied information science 2, 4-11 (2018). (In Russ.)

[5] Ostroukh, E. N., Chernyshov, Yu. O., Klimova, D. $\mathrm{N}$. Solving the problem of modeling business processes of an IT company using the swarm intelligence method. International research journal, vol. 3, no. 9, 53-57 (2017). (In Russ.)

[6] Artemov, O. V. Managing internal team integration. In: Intellectual capital management 2007. International conference materials, pp. 91-95. Publ. VlGU, Vladimir (2007). (In Russ.)

[7] Budyl'skiy, A. V., Kvyatkovskaya, I. Yu. Managing software development projects using agent-based technologies. Caspian Journal: Management and High Technologies 3(23), 119-128 (2013). (In Russ.)

[8] Antonova, A. S., Aksenov, K. A. Application of multi-agent and evolutionary modeling in work planning. Scientific and technical statements SPbGPU. Informatics. Telecommunications. Control 6(186), 126-136 (2013). (In Russ.)

[9] Burkova, I. V. Method of network programming in problems of nonlinear optimization. Automation and telemechanics 10, 15-21 (2009). (In Russ.)

[10] Boehm, B., et al. Software cost estimation with COCOMO II. Prentice-Hall, Englewood Cliffs, NJ (2000).

[11] Podvesovskii, A. G., Mikhaleva, O. A. (et. al.) A Model of Control of Expert Estimates Consistency in Distributed Group Expertise. A. Kravets et al. (Eds.):
CIT\&DS 2017, Communications in Computer and Information Science, Vol. 754, Springer International Publishing AG 2017, pp. 361-374. doi: 10.1007/978-3-319-65551-2 26 (2017).

[12] Barricelli, N. A. Symbiogenetic evolution processes realized by artificial methods. Methodos 9(35-36), 143-182 (1957).

[13] Saymon, D. Evolutionary optimization algorithms. DMK Press, Moscow (2020). (In Russ.)

[14] Belbin, R. M. Types of roles in management teams. HIPPO, Moscow (2003). (In Russ.)

[15] Vaynilovich, Yu.V. Problems of competencies development of IT projects teams / In: M. E. Lustenkov (ets.) Materials, equipment and resourcesaving technologies: materials of the international scientific and technical conf. 2019, pp. 408-409. Belarusian-Russian University, Mogilev (2019). (In Russ.)

[16] Vaynilovich, Yu. V., Zakharchenkov K. V. Program complex of multilevel IT project management. Innovation 8(250), 88-96 (2019). (In Russ.)

[17] Zakharchenkov, K. V., Mrochek, Zh. A., Mrochek, T. V. Algorithm for solution of multicriterion problem of production planning of pipes and shaped products. System analysis and applied information science 4, 4-10 (2018). (In Russ.)

[18] Zakharchenkov, K.V., Vaynilovich Yu.V. Methodology for multilevel management of educational IT projects. In: Energy, innovation, innovation - 2018 (innovative technologies and equipment in industry, innovation management, economics and management, scientific research in the field of physical culture, sports and social sciences): Proceedings of the VIII International Scientific and Technical Conference, vol 3, pp. 1821. «Universum», Smolensk (2018). (In Russ.)

[19] Borisov, V. V., Yanukovich, S. P., Zakharchenkov, K. V., Vaynilovich, Yu.V. A method for managing the process of teaching industrial programming based on swarm intelligence algorithms. CloudOfScience, vol.7, no. 1, pp. 189-206 (2020). (In Russ.)

\section{About the authors}

Alena A. Zakharova, Sc.D. in Technique, professor of Informatics and Software Engineering Department at Bryansk State Technical University. E-mail: zaa@tu-bryansk.ru

Konstantin V. Zaharchenkov, Ph.D. (Engineering), Associate Professor, Department of Automated Control Systems, Inter-State Educational Institution of Higher Education «Belarusian-Russian University», Mira Ave, 43, Mogilev, 212000, Republic of Belarus, E-mail: zaharchenkovkv@mail.ru

Julija V. Vajnilovich, Senior Lecturer, Department of Automated Control Systems, Inter-State Educational Institution of Higher Education «Belarusian-Russian University», Mira Ave, 43, Mogilev, 212000, Republic of Belarus, E-mail: Ylia.v@tut.by 